\title{
Análise de parâmetros hematimétricos e bioquímicos em equinos da raça Quarto de Milha atletas pré e pós-treinamento
}

\section{Pre and post-training analysis of hematimetric and biochemical parameters in athletic Quarter Horses}

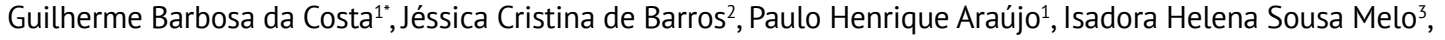 \\ Mariana Reato Nascimento ${ }^{4}$, Izabela Puerchi Ribeiro ${ }^{1}$, Guilherme Henrique Souza Rocha ${ }^{1}$, Daniel Paulino Junior ${ }^{2}$ \\ ${ }^{1}$ Medicina Veterinária, Universidade de Franca (UNIFRAN), Franca, SP, Brasil \\ 2 Programa de Pós-graduação em Ciência Animal, Universidade de Franca (UNIFRAN), Franca, SP, Brasil \\ ${ }_{3}^{3}$ Programa de Aprimoramento em Extensão Rural, Universidade de Franca (UNIFRAN), Franca, SP, Brasil \\ ${ }^{4}$ Programa de Aprimoramento em Patologia Clínica e Animal, Universidade de Franca (UNIFRAN), Franca, SP, Brasil
}

\section{Resumo}

A interação entre homem e cavalo vem crescendo ao longo dos anos. A espécie foi destacada pelas habilidades de transporte e trabalho e, atualmente, por modificações em suas funções zootécnicas, evidencia-se pelo esporte e entretenimento. Com o avanço da tecnologia e com o intuito de desenvolver eaprimorar as caraterísticas físicas destes animais para as modalidades esportivas, estudos relacionados ao condicionamento físico e a variáveis como desempenho cardiorrespiratório, hemodinâmico e metabólico são destaque nas linhas de pesquisa da comunidade científica. Diante disso, objetivou-se com esse estudo analisar e descrever as principais alterações entre os períodos de pré e pós-treinamento de cavalos que são submetidos a exercício físico de alto rendimento. Para obtenção dos resultados foram utilizados 13 equinos da raça Quarto de Milha, durante três meses, sem que fossem alteradas as formas de treinamento; as dosagens séricas de lactato, creatina quinase, glicose e hemograma foram coletadas pré e pós-treinamento. Concluiu-se que os valores de hemácia, hemoglobina, volume corpuscular médio (VCM) e concentração da hemoglobina corpuscular média (CHCM) aumentam aproximadamente $35 \%$ em equinos que competem em provas de explosão, comparando os momentos de pré e pós-treinamento. Durante o pré-treinamento, os valores de creatina quinase aumentaram em média $85 \%$ entre os intervalos de avaliação e houve uma oscilação entre os resultados no pós-treino. 0 lactato sérico pode apresentar valores $500 \%$ maiores em períodos pós-treinamento, com uma tendência de diminuição com a melhora do condicionamento físico do animal; além deste, a glicemia também diminuiu ao longo dos treinamentos, sendo evidenciada diminuição no metabolismo energético.

Palavras-chave: Cavalo. Esportes equestres. Hemograma. Lactato. 


\section{Abstract}

The interaction between man and horse has been growing over the years. The species was distinguished by the abilities of transport, work and, currently, due to modifications in its zootechnical functions, by the abilities of sport and entertainment. With the advancement of technology, and with the aim of developing and improving the physical characteristics of these animals for sports, studies related to physical conditioning and variablessuch ascardiorespiratory, hemodynamic and metabolic performance are highlighted in the lines of research of the scientific community. Therefore, this study aimed to analyze and describe the main changes between the pre and post-training periods of horses that are submitted to high-performance physical exercise. In order to obtain these results, 13 horses of the Quarter Horse breed were used during three months, without altering the training methods; the serum levels of lactate, creatine kinase, glucose and hemogram were collected before and after the training. It was concluded that the values of hemoglobin, hemoglobin, mean corpuscular volume (MCV) and mean corpuscular hemoglobin concentration (CHCM) increased approximately 35\% in horses competing in fast sprint training, comparing pre- and post-training moments. During pre-training, CK values increased by an average of $85 \%$ between the assessment intervals, and there was an oscillation between the post-workout results. Serum lactate can present 500\% higher values in post-training periods, with a tendency to decrease with the improvement of the physical condition of the animal; in addition to this, glycemia also decreased during the training, being evidenced a decrease in energy metabolism.

Keywords: Horse. Equestrian sports. Blood count. Lactate.

\section{Introdução}

A medicina esportiva equina é uma área relativamente nova, surgida no final de 1950, momento em que o homem modificou a função zootécnica do cavalo, passando-o de ferramenta de trabalho a nível esportista (Melo et al., 2015). Em decorrência desta demanda, novas pesquisas se tornaram necessárias, pois o alto desempenho dos animais pode ter como consequência desequilíbrios metabólicos e funcionais (Rivero e Hill, 2016).
0 condicionamento físico e a manutenção deste processo são de fundamental importância para todos os cavalos que são submetidos a qualquer tipo de exercício, preparando o atleta, induzindo adaptações fisiológicas necessárias para um bom rendimento e diminuindo o risco de lesão, seja de origem muscular ou cardiovascular. A precoce percepção dessas alterações permite intervenção efetiva, melhorando o prognóstico das enfermidades, diminuindo o custo dos tratamentos e minimizando o risco de morte súbita, consequência mais grave dos atletas de alto desempenho (Rivero e Hill, 2016). Para que isso ocorra, existem váriavéis que podem ser analisadas de forma minimamente invasiva, com baixo custo, sendo aplicáveis na rotina e obtendo resultados satisfatórios para a análise fisiológica dos equinos atletas.

O lactato sérico é oriundo da atividade anaeróbica da glicose, liberando energia sob forma de ATP (adenosina trifosfato). Este feito é importante pois, durante a prática de exercícios, em casos de oferta de oxigênio insuficiente, torna-se uma via alternativa de energia (Balarin et al., 2005). 0 estudo pioneiro de Pilis et al. (1988) afirma que todo exercício anaeróbico tende a induzir um aumento transitório da enzima lactato desidrogenase (LDH) em um período de 24 horas pós-exercício, tendo uma correlação positiva com os valores de lactato sanguíneo. $\mathrm{O}$ acúmulo de lactato no músculo e consequente acidose intracelular podem interferir negativamente na glicólise, reduzindo a respiração celular, resultando em desequilíbrio da homeostase e interferindo na relação ADP (adenosina difosfato)/ ATP no sítio de ligação miosina-actina (Couroucé et al., 1997, Balarin et al., 2005).

O exercício físico promove efeitos variados no eritrograma, dependendo da sua duração e intensidade. Além disso, fatores como raça, idade, sexo e alimentação podem influenciar nos valores do hemograma (Balarin et al., 2006).

No eritrograma, faz-se a avaliação do número de hemácias, volume globular (VG), volume corpuscular médio (VCM), concentração de hemoglobina corpuscular média (CHCM) e hemoglobina corpuscular média (HCM) (Piccione et al., 2001).

A principal função dos eritrócitos é o transporte de oxigênio, portanto, para que um animal atleta 
apresente performance máxima, a distribuição de oxigênio no tecido muscular deve ser adequada. 0 maior consumo de oxigênio durante o exercício, porém, induz uma produção excessiva de metabólitos altamente reativos, denominados espécimes reativas de oxigênio (EROs), que promovem lesões oxidativas na camada lipídica proteica da membrana dos eritrócitos, sendo estes causadores de hemólise oxidativa, levando à queda no número de eritrócitos e na avaliação do hematócrito (Machado, 2006). A creatina quinase (CK) é uma enzima presente em todos os tecidos musculares e que intervém no processo de produção de energia a nível muscular. Sua função predominante ocorre nas células musculares, principalmente musculatura esquelética, cardíaca e cerebral, onde está envolvida no estoque de creatina fosfato (altamente energético). Uma maior concentração sérica pode ocorrer em condições de estresse físico (Martins et al., 2005), portanto, na prática atlética equestre é comum o aumento da concentração de CK na corrente sanguínea, podendo estar associado ou não à lesão muscular por fadiga (Corrêa et al., 2010).

0 metabolismo anaeróbio de glicose representa um imprescindível e rápido mecanismo de obtenção de energia, embora seja de baixa produção de ATP. Vários fatores regulam a atividade da via glicolítica, como a disponibilidade de oxigênio e a relação das concentrações de ATP/ ADP. Diminuições na relação ATP/ADP estimulam a glicólise anaeróbica, aumentando em até 100 vezes a produção de moléculas de piruvato. Entretanto, à medida que se aumenta a intensidade do exercício, atinge-se um ponto em que uma quantidade insuficiente de oxigênio está disponível para a fosforilação oxidativa, e que uma proporção de NADH2 (dinucleótido de nicotinamida e adenina) é reoxidada, via piruvato, sendo metabolizado o lactato. À medida que a intensidade do exercício aumenta, maior quantidade de lactato é produzida e uma maior proporção de energia é suprida pelas vias anaeróbias (Ferraz et al.,2010).

0 objetivo desse estudo, portanto, é analisar e descrever as principais alterações entre os períodos de pré e pós-treinamento de cavalos que são submetidos a exercício físico de alto rendimento, participantes de corrida hípica.

\section{Material e métodos}

0 estudo teve duração de 90 dias, sendo 30 dias de adaptação e 60 dias de coleta. Foram utilizados 13 equinos da raça Quarto de Milha (QM), com idade entre 5 e 15 anos e variação de peso de 350 a $550 \mathrm{~kg}$. A pesquisa foi realizada sob vigência do Comitê de Ética no Uso de Animais (CEUA), sob o protocolo 69101003/17.

Com o intuito de avaliar o desempenho atlético dos animais em prova de corrida hípica, o circuito foi composto por uma pista de areia de $600 \mathrm{~m} \mathrm{de}$ comprimento por $60 \mathrm{~m}$ de largura. 0 tempo médio de cada cavalo em competição foi de 60 segundos, e o intervalo entre animais na pista variou entre $5 \mathrm{e}$ 10 minutos.

Os tempos de execução do estudo foram de T0 (primeira coleta de material e avaliação clínica, com adaptação prévia de 30 dias dos equinos com os pesquisadores), T15, T30, T45 e T60. Em todos os tempos descritos, no momento pré-treinamento os dados foram coletados até 40 minutos antes da prova, e no pós-treinamento, imediatamente após o cavalo sair da pista de competição.

Cronograma Total de 90 dias

\begin{tabular}{|l|l|l|l|}
\hline Período de daptação & \multicolumn{3}{c|}{ Período de Coletas:60 dias } \\
\hline \multicolumn{1}{|c|}{30 dias } & T15 & T30 & Término da \\
Pesquisa
\end{tabular}

Para a coleta de sangue, foi preconizado o acesso venoso jugular, utilizando tubos de vacutainer com agulhas específicas. Para o hemograma, foi utilizado tubo com EDTA (ácido etilenodiamino tetra-acético), e para a dosagem de CK, tubo seco. Para dosagem de glicose, utilizou-se medidor e fitas teste específicas, e a mensuração de lactato se deu por medidor portátil, também com fitas teste específicas.

Para a avaliação dos dados, foi preconizada a análise descritiva das variáveis quantitativas; os dados estão apresentados na forma de média e desvio padrão. Foi empregado o programa computacional GraphPadPrism v. 7 para análise das 
variáveis, sendo as mesmas submetidas à análise de variância (ANOVA) e teste $\mathrm{t}$ de Student. 0 nível de significância estabelecido foi de $5 \%$.

\section{Resultados e discussão}

Com os resultados obtidos na avaliação dos parâmetros hematológicos (Tabela 1), nota-se uma variação de aproximadamente $35 \%$ nos valores de hemácias e hemoglobina entre os períodos de pré e pós-treinamento. Tal fato pode estar relacionado com a contração esplênica durante o exercício, com o objetivo de manter e otimizar a oferta de oxigênio. Outra justificativa seria a hemoconcentração oriunda da perda de fluídos corporais (Hodgson et al., 2014).

Em relação aos resultados de CK (Tabela 2), observa-se que nas avaliações pré-treinamento houve um aumento aproximado de $100 \%$ no T15 e T30; e quando comparados T15 e T60, houve $75 \%$ de aumento. No pós-treino, a oscilação mais relevante ocorreu no T30, onde os valores médios ultrapassaram os aceitáveis. Confome Hodgson et al. (2014), valores aceitáveis de CK para equinos variam entre 100 a 300 UI/L. Já Meyer et al. (1995) utilizam valores menores de referência, variando de 86 a 140 UI/L. Harris et al. (1998), entretanto, descrevem que pode haver variação entre os equinos devido às altas atividades enzimáticas e sua lenta disseminação pela circulação, promovendo lenta eliminação. Além disso, alguns cavalos possuem uma maior sensibilidade quanto à permeabilidade da membrana celular muscular, favorecendo tais variações. Toledo et al. (2001) descrevem que os valores padrões de CK sofrem elevações significativas quando os equinos são submetidos a exercícios de moderada à alta intensidade.

Alguns autores já relataram ação enzimática relacionada com o quadro de lesão muscular. Valberg et al. (1993) relatam que o pico de elevação ocorre aproximadamente entre quatro e seis horas após a lesão. Já Harris et al. (1998) descrevem elevação duas horas após o exercício, resultante das microlesões musculares. Corrêa et al. (2010) apresentam análises em que a $\mathrm{CK}$ se eleva seis a 48 horas após a injúria muscular. Sendo assim, no presente estudo não foi possível a confirmação da ocorrência de lesões, pois a análise foi realizada no momento pós-exercício imediato.

Tabela 1 - Médias e desvio padrão dos parâmetros hematológicos de cavalos Quarto de Milha pré e pós-treinamento

\begin{tabular}{lcccccccc}
\hline & \multicolumn{2}{c}{ T15 } & \multicolumn{2}{c}{ T30 } & \multicolumn{2}{c}{ T45 } & \multicolumn{2}{c}{ T60 } \\
& Pré-treino & Pós-treino & Pré-treino & Pós-treino & Pré-treino & Pós-treino & Pré-treino & Pós-treino \\
\hline Hemácias* & $10,3 \pm 1,1$ & $14,0 \pm 0,7$ & $10,6 \pm 1,1$ & $15,0 \pm 1,0$ & $10,5 \pm 0,9$ & $14,6 \pm 1,0$ & $10,6 \pm 1,0$ & $15,0 \pm 1,2$ \\
Hemoglobina** $^{*}$ & $15,6 \pm 1,8$ & $22,1 \pm 1,1$ & $16,2 \pm 1,3$ & $22,6 \pm 0,9$ & $16,0 \pm 1,3$ & $22,1 \pm 1,1$ & $16,3 \pm 1,5$ & $22,5 \pm 1,7$ \\
VCM $^{* * *}$ & $44,8 \pm 1,7$ & $46,2 \pm 1,5$ & $44,8 \pm 1,7$ & $46,2 \pm 2,0$ & $45,1 \pm 1,7$ & $45,6 \pm 1,2$ & $45,3 \pm 1,6$ & $46,8 \pm 1,8$ \\
CHCM $^{* * * *}$ & $34,6 \pm 1,7$ & $33,1 \pm 0,3$ & $34,2 \pm 1,0$ & $33,5 \pm 0,5$ & $34,1 \pm 0,7$ & $33,3 \pm 0,8$ & $33,9 \pm 0,7$ & $32,8 \pm 0,7$ \\
\hline
\end{tabular}

Nota: ${ }^{*} p<0,000003 ;{ }^{* *} p<0,0000001 ;{ }^{* * *} p<0,005 ;{ }^{* * * *} p<0,003$ - Comparativo entre T15 a T60.

VCM = volume corpuscular médio; $C H C M=$ concentração de hemoglobina corpuscular média.

Tabela 2 - Média e desvio padrão dos valores de creatina quinase (CK) em cavalos Quarto de Milha pré e pós-treinamento

\begin{tabular}{|c|c|c|c|c|c|c|c|c|}
\hline & \multicolumn{2}{|c|}{ T15 } & \multicolumn{2}{|c|}{ T30 } & \multicolumn{2}{|c|}{$\mathrm{T} 45$} & \multicolumn{2}{|c|}{ T60 } \\
\hline & Pré-treino & Pós-treino & Pré-treino & Pós-treino & Pré-treino & Pós-treino & Pré-treino & Pós-treino \\
\hline $\mathrm{CK}^{*}$ & $141,5 \pm 39,8$ & $280,8 \pm 218,5$ & $289,0 \pm 167,8$ & $332,2 \pm 120,7$ & $140,1 \pm 35,0$ & $230,5 \pm 118,9$ & $248,1 \pm 160,7$ & $296,9 \pm 102,9$ \\
\hline
\end{tabular}

Nota: * $p$ > 0,11 - Comparativo entre T15 a T 60. 
$\mathrm{Na}$ análise da concentração de lactato plasmático (Tabela 3), observa-se que nas mensurações prétreinamento o T15 foi o tempo com valores mais elevados, e o mesmo achado é válido quando descrevemos os resultados de pós-treinamento. A adaptação dos animais juntamente com a evolução condicionamento são fatores relevantes, pois há diminuição entre T15 e T60, sendo preconizado que com o aumento do condicionamento e possível diminuição do metabolismo muscular possa ocorrer o favorecimento do desempenho dos animais

0 aumento da concentração de lactato no póstreino é decorrente do exercício intenso e consumo de energia, utilizando a anaerobiose como fonte alternativa energética (Seeherman e Morris, 1990). Estudos dizem que os níveis de lactato sérico retornam ao padrão basal aproximadamente duas horas após o término do exercício físico, e o desempenho atlético do animal influencia diretamente nos níveis de lactato apresentados (Couroucé et al., 1997). Em todos os tempos analisados, o lactato pós-treinamento foi maior que $500 \%$ quando comparado ao período em que os animais estavam em repouso. Há uma tendência de que, com o avanço dos treinos, o lactato pré-treinamento reduza seus valores, tendo em vista os resultados obtidos (Figura 1).

Tabela 3 - Médias e desvio padrão dos valores de lactato em cavalos Quarto de Milha pré e pós-treinamento

\begin{tabular}{|c|c|c|c|c|c|c|c|c|}
\hline & \multicolumn{2}{|c|}{ T15 } & \multicolumn{2}{|c|}{ T30 } & \multicolumn{2}{|c|}{ T45 } & \multicolumn{2}{|c|}{ T60 } \\
\hline & Pré-treino & Pós-treino & Pré-treino & Pós-treino & Pré-treino & Pós-treino & Pré-treino & Pós-treino \\
\hline Lactato & $3,4 \pm 0,5^{*}$ & $17,8 \pm 3,4^{*}$ & $2,5 \pm 0,9$ & $14,7 \pm 2,9$ & $2,7 \pm 0,4$ & $15,7 \pm 2,8$ & $1,15 \pm 0,3^{*}$ & $14,84 \pm 5,8^{*}$ \\
\hline
\end{tabular}

Nota: ${ }^{*} p<0,000004$ - Comparativo T15 a T60.

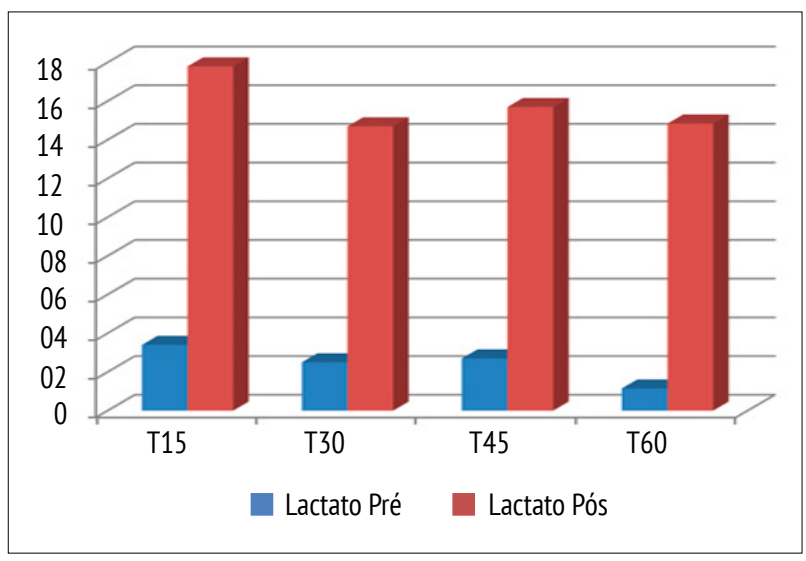

Figura 1 - Valores de lactato obtidos durante o pré e pós-treino.

O lactato está diretamente relacionado ao metabolismo anaeróbico e aumento da necessidade energética muscular. Nota-se que a elevação da glicose sérica no T15 é proporcional à elevação do lactato no mesmo dia, demostrando a utilização da via anaeróbica para metabolização de lactato e o fornecimento de energia, justificando o aumento glicêmico pós-exercício (Corrêa et al., 2010).

Em estudo conduzido com cavalos de enduro, a concentração de glicose sérica não sofreu alteração nos valores de referência nos $42 \mathrm{~km}$ de prova. Já em exercícios de explosão, como a corrida hípica, por exemplo, há uma tendência ao aumento da glicemia entre o pré e pós-treinamento. Ao longo da pesquisa, com o condicionamento físico e preparo dos atletas, ocorreu diminuição ao se comparar T15 pré com T60 pré, T15 pós com T60 pós (Tabela 4), porém o aumento glicêmico continuou ocorrendo (Martins et al.,2005).

Tabela 4 - Médias e desvio padrão dos valores de glicose sérica em cavalos Quarto de Milha pré e pós-treinamento

\begin{tabular}{|c|c|c|c|c|c|c|c|c|}
\hline & \multicolumn{2}{|c|}{ T15 } & \multicolumn{2}{|c|}{ T30 } & \multicolumn{2}{|c|}{ T45 } & \multicolumn{2}{|c|}{$\mathrm{T} 60$} \\
\hline & Pré-treino & Pós-treino & Pré-treino & Pós-treino & Pré-treino & Pós-treino & Pré-treino & Pós-treino \\
\hline Glicose & $90,0 \pm 10,3^{*}$ & $127,3 \pm 23,0^{*}$ & $84,5 \pm 5,4$ & $113,7 \pm 17,8$ & $85,1 \pm 6,9$ & $115,7 \pm 17,3$ & $84,6 \pm 10,8^{*}$ & $103,5 \pm 24,2^{*}$ \\
\hline
\end{tabular}

Nota: ${ }^{*} p<0,001$ - Comparativo T15 a T60. 


\section{Conclusão}

Nota-se que em cavalos atletas expostos a exercícios de explosão, os principais achados de avaliação dos parâmetros hematológicos foram valores de hemácia, hemoglobina, VCM e CHCM, que aumentaram aproximadamente $35 \%$, comparando os momentos de pré e pós-treinamento. Já os valores de CK aumentaram em média $85 \%$ entre pré e póstreino, T15 a T 60 , sendo observada uma oscilação entre T30 e T45. A glicose sérica apresentou redução com a evolução dos treinamentos, melhora da condição atlética dos equinos e duração dos treinos, sendo T60 < T15. Pode-se observar que o lactato sérico apresentou valores 500\% maiores em períodos pós-treinamento, com uma tendência de diminuição com a melhora do condicionamento físico do animal, sendo evidenciada a redução das condições pré e pós-treino no comparativo entre T15 e T60.

\section{Referências}

Balarin MRS, Lopes RS, Kohayagawa A, Laposy CB, Fonteque JH. Assessement of glycaemia and serum activities of aspartate aminotransferase, creatinekinase, gamma glutamyltransferase and lactate dehydrogenase in thoroughbred horses submitted to exercise of different intensities. Semina Cienc Agrar. 2005;26(2):211-8.

Balarin MRS, Lopes RS, Kohayagawa A, Laposy CB, Fonteque JH. Valores da Amplitude de Distribuição do Tamanho dos Eritrócitos (RDW) em equinos Puro Sangue Inglês (PSI) submetidos a exercícios de diferentes intensidades. Braz J Vet Res Anim Sci. 2006;43(5):637-41.

Corrêa KS, Mattoso CRS, Silva CFGKT, Lagos MS, Takahira, RK, Lopes RS. Enzimas musculares e eletrólitos em equinos submetidos a esforço físico prolongado, suplementados com acetato de tocoferol e selênio. Vet Zootec. 2010;17(1):85-93.

Couroucé A, Chatard JC, Auvinet B. Estimation of performance potential of standardbred trotters from blood lactate concentrations measured in field conditions. Equine Vet J.1997;29(5):365-9.
Ferraz GC, Teixeira-Neto AR, Pereira MC, Linardi RL, Lacerda-Neto JC, Queiroz-Neto A. Influência do treinamento aeróbio sobre o cortisol e glicose plasmáticos em equinos. Arq Bras Med Vet Zootec. 2010;62(1):23-9.

Harris PA, Marlin DJ, Gray J. Plasma aspartate aminotransferase and creatine kinase activities in thoroughbred racehorses in relation to age, sex, exercise and training. Vet J. 1998;155(3):295-304.

Hodgson DR, McKeever KH, McGowan CM. The athletic horse: principles and practice of equine medicine. St. Louis, Missouri: Elsevier Saunders; 2014. p. 397.

Machado LP. Eritrograma glutationa reduzida e superóxido dismutase eritrocitários e metahemoglobina em equinos da raça Árabe submetidos a exercício em esteira: efeito da suplementação com vitamina E (dl-alfatocoferol) [dissertação]. Botucatu: Universidade Estadual Paulista; 2006. 99 p.

Martins CB, Orozco CAG, D'Angelis FHF, Freitas EVV, Christovão FG, Queiroz Neto $\mathrm{A}$, et al. Determinação de variáveis bioquímicas em eqüinos antes e após a participação em prova de enduro. $\mathrm{R}$ Bras Ci Vet. 2005;12(1-3):62-5.

Melo IHS, Pereira LF, Casas VF, Junior DP. Achados eletrocardiográficos e níveis de lactato sanguíneo em equinos submetidos ao exercício. Investigacao. 2015;14(2):104-12.

Meyer DJ, Coles EH, Rich LJ. Medicina de Laboratório Veterinária. São Paulo: Roca;1995. p. 308.

Piccione G, Assenza A, Fazio F, Giudice E, Caola G. Different Periodicities of Some Haematological Parameters in Exercise-Loaded Athletic Horses and Sedentary Horses. J Equine Sci. 2001;12(1):17-23.

Pilis W, Langfort J, Pilsniak A, Pyzik M, Btasiak M. Plasma lactate dehydrogenase and creatine kinase after anaerobic exercise. Int J Sports Med.1988;9(2):102-3.

Rivero JLL, Hill EW. Skeletal muscle adaptations and muscle genomics of performance horses. Vet J. 2016;209:5-13. 
Seeherman HJ, Morris EA. Application of a standardised treadmill exercise test for clinical evaluation of fitness in 10 thoroughbred racehorses. Equine Vet J Suppl. 1990;(9):26-34.

Toledo PS, Domingues Jr M, Fernandes WR, Magone M. Atividade sérica de aspartato aminotransferase, creatina quinase, gama-glutamiltransferase, lactato desidrogenase e glicemia de cavalos da raça PSI submetidos a exercícios de diferentes intensidades. R Bras Ci Vet. 2001;8(2):73-7.

Valberg S, Häggendal J, Lindholm A. Blood chemistry and skeletal muscle metabolic responses to exercise in horses with recurrent exertional rhabdomyolysis. Equine Vet J. 1993;25(1):17-22. 